\title{
Comparison of intraoral digital radiography and cone-beam computed tomography in the measurement of periodontal bone defects
}

\section{Porównanie radiografii cyfrowej i tomografii stożkowej w ocenie wielkości periodontologicznych ubytków kostnych}

\author{
Mehrdad Abdinian ${ }^{1, A, B, E, F}$, Jaber Yaghini ${ }^{2, A, E, F}$, Leila Jazi ${ }^{3, B-D}$ \\ 1 Department of Oral and Maxillofacial Radiology, Dental Implants Research Institute, School of Dentistry, Isfahan University of Medical Sciences, Iran \\ ${ }^{2}$ Department of Periodontics, Dental Implants Research Institute, School of Dentistry, Isfahan University of Medical Sciences, Iran \\ ${ }^{3}$ Department of Orthodontics, School of Dentistry, Tehran University of Medical Sciences, Iran \\ A - research concept and design; B - collection and/or assembly of data; $\mathrm{C}$ - data analysis and interpretation; \\ $D$ - writing the article; $E$ - critical revision of the article; $F$ - final approval of the article
}

Address for correspondence

Leila Jazi

E-mail: leilajazi@yahoo.com

Funding sources

Isfahan University of Medical Sciences, Iran

Conflict of interest

None declared

Received on 0ctober 30, 2019

Reviewed on November 27, 2019

Accepted on March 4, 2020

Published online on September 30, 2020

Cite as

Abdinian M, Yaghini J, Jazi L. Comparison of intraoral digital radiography and cone-beam computed tomography in the measurement of periodontal bone defects. Dent Med Probl. 2020;57(3):269-273. doi:10.17219/dmp/118749

DOI

$10.17219 / \mathrm{dmp} / 118749$

Copyright

○) 2020 by Wroclaw Medical University

This is an article distributed under the terms of the

Creative Commons Attribution 3.0 Unported License (CC BY 3.0)

(https://creativecommons.org/licenses/by/3.0/).

\section{Abstract}

Background. Periodontal disease has a high prevalence in many countries. Thus, the early detection of periodontal disease is important in order to obtain the most appropriate treatment plan to prevent tooth loss, and subsequently, to maintain the patient's general health.

Objectives. The aim of this study was to compare the accuracy of cone-beam computed tomography (CBCT) and intraoral parallel digital radiography in measuring the dimensions of periodontal bone defects.

Material and methods. In this in vitro study, 236 periodontal bone defects were artificially created in dry human mandibles using a burr. Defects included horizontal, one-, two-, and three-wall defects, craters, dehiscences, and fenestrations. Intraoral digital radiographs were obtained using the parallel technique with photostimulable phosphor plates (PSP) and CBCT scans were performed. Two calibrated observers evaluated the images and measured the dimensions of the defects. Clinical probing was performed and considered as the gold standard. The measurements of digital radiography and CBCT were compared to those achieved by probing to evaluate their accuracy.

Results. Cone-beam computed tomography had a significantly stronger correlation with the gold standard than intraoral parallel digital imaging. In the total assessment of the periodontal defects, the intraclass correlation coefficient (ICC) was calculated at 0.93 for CBCT-probe and at 0.78 for PSP-probe $(p<0.05)$.

Conclusions. The accuracy of CBCT was superior to that of intraoral digital radiography for measuring horizontal, one-, two-, and three-wall defects, craters, dehiscences, and fenestrations.

Key words: cone-beam computed tomography, radiography, alveolar bone loss, dental

Słowa kluczowe: tomografia stożkowa, radiografia, zanik wyrostka zębodołowego, dentystyczny 


\section{Introduction}

Periodontal disease has a high prevalence in many countries. ${ }^{1}$ The early detection of periodontal disease is important in preventing tooth loss, and subsequently, maintaining the patient's general health. ${ }^{2}$ Conventional diagnostic methods for periodontal disease include probing gingival tissues and performing radiographs to evaluate bony support. ${ }^{3}$ Radiographs give us information about the amount and type of alveolar bone defect. ${ }^{4}$ Hence, they are valuable in the detection of bone defects, the estimation of their severity, the evaluation of the treatment outcome, and making prognosis. ${ }^{5}$

The digitalization of intraoral radiographs has eliminated the processing of chemical compounds and lead foils. It made digital subtraction radiography (DSR) useful for lesion follow-up. ${ }^{6}$ Also, digital radiography has a highly decreased radiation dose. It has some other advantages over conventional methods, including time efficiency and image enhancement. ${ }^{7}$

Using two-dimensional (2D) radiographic methods, we can only observe the interproximal surfaces, and as a result, bone loss may be underestimated due to having a 2D view of three-dimensional (3D) structures. Difficulty in finding a reliable reference point can be another outcome. ${ }^{8}$ Moreover, the superimposition of anatomical structures in 2D imaging may cause errors in measuring the distance between the buccal and lingual cortical plates. ${ }^{2}$ However, the parallel projection technique of performing periapical radiographs results in a minimal geometric distortion. ${ }^{9}$ It also costs less than $3 \mathrm{D}$ imaging.

On the other hand, cone-beam computed tomography $(\mathrm{CBCT})$ provides high-quality images. Structures can be assessed in 3 dimensions at different planes and at any angle, with no overlapping, making it possible to carry out an analysis without distortions and to measure bone defects even of the buccal and lingual plates. $^{10}$

Measuring precisely the dimensions of a vertical periodontal defect is pivotal when planning an appropriate therapeutic intervention, such as regenerative therapy. ${ }^{11-13}$

Considering the high prevalence of periodontal disease and rapid advances in new imaging techniques, we need to compare their accuracy in measuring the dimensions of periodontal defects. A few studies with small sample sizes and limited types of periodontal defects have been done regarding this aspect, and more investigations are needed to show whether CBCT is a suitable modality for periodontal tissues. ${ }^{14,15}$ The aim of this study was to compare the accuracy of CBCT and parallel periapical digital radiography in measuring simulated periodontal defects.

\section{Material and methods}

For this descriptive-analytic study, 11 mandibles of dry human skulls were used in 2017. A total of 236 artificial defects, including horizontal, one-, two-, and three-wall defects, craters, dehiscences, and fenestrations, were created with a No. $1 / 2$ round burr and a No. 1 fissure burr. In all, 86 horizontal defects, 30 one-wall defects, 20 twowall defects, 22 three-wall defects, 22 craters, 32 dehiscences, and 24 fenestrations were prepared in this study.

The cementoenamel junction (CEJ) was considered as the reference point. For one-, two- and three-wall defects as well as for dehiscences, the dimensional measurement of the maximum depth (from CEJ to the bottom of the defect) was done by a periodontist using the WHO (World Health Organization) periodontal probe. For craters, the maximum distance from the CEJ of the tooth, mesial to the crater, to the deepest point of the crater was measured. The mesiodistal width of fenestrations was recorded and the maximum distance from CEJ to the alveolar bone crest was measured in order to evaluate bone loss in horizontal defects. The dimensions were marked on the probe, and then measured by a digital caliper (Guilin Guanglu Measuring Instrument Co. Ltd, Guilin, China).

Before applying imaging modalities, the soft tissue was simulated by putting the mandibles into a plexiglass box full of water. The holder was anchored to the box and the teeth with tape.

Intraoral digital radiographs were taken with the parallel technique, using a size 2 photostimulable phosphor plate (PSP) (VistaScan ${ }^{\circledR}$; Dürr Dental SE, Bietigheim-Bissingen, Germany), the $\mathrm{XCP}^{\circledR}$ sensor holder (Dentsply Rinn, Charlotte, USA), and an intraoral X-ray unit (Planmeca, Helsinki, Finland) at a focal spot-object distance (FOD) of $30 \mathrm{~cm}$. The exposure was set up at $60 \mathrm{kvp}$ with $0.8 \mathrm{~mA}$. The dimensions were measured with the Scanora ${ }^{\mathbb{B}}$ 4.3.1.1 software (Soredex, Tuusula, Finland) (Fig. 1).

Then, CBCT scanning was carried out with a CBCT unit (Dentsply Sirona, Helsinki, Finland). The exposure setting was $89 \mathrm{kvp}$ and $6 \mathrm{~mA}$ at a $12 \times 8$-centimeter field of view (FOV). The isotropic voxel size was $0.25 \mathrm{~mm}$. Cone-beam computed tomography images were evaluated with the

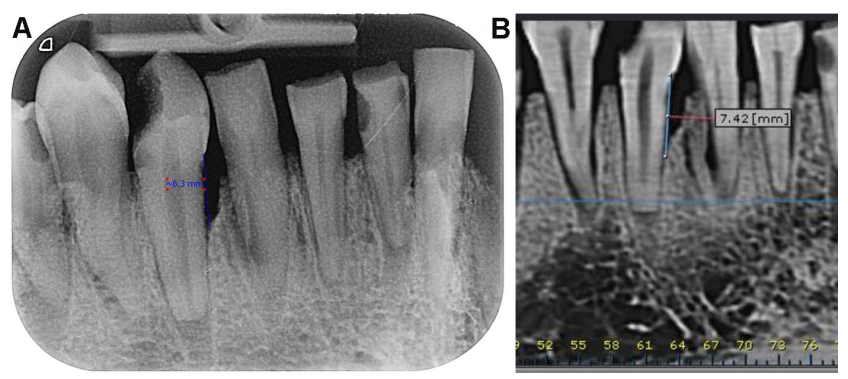

Fig. 1. Three-wall defect at the mesial side of a canine

A - intraoral digital radiograph; $B$ - panoramic reconstruction view of the cone-beam computed tomography (CBCT) scan. 
OnDemand3D ${ }^{\circledR}$ software (Cybermed Inc., Seoul, South Korea). They were reconstructed into 3D models to measure dehiscences and fenestrations whereas panoramic views (a slice thickness of $2 \mathrm{~mm}$ ) were used for measuring the dimensions of other defects. The reason for this was that scrolling the panoramic reconstructions to find the deepest point of dehiscences and the maximum width of fenestrations was problematic, and could provide inaccurate measurements (Fig. 1,2).

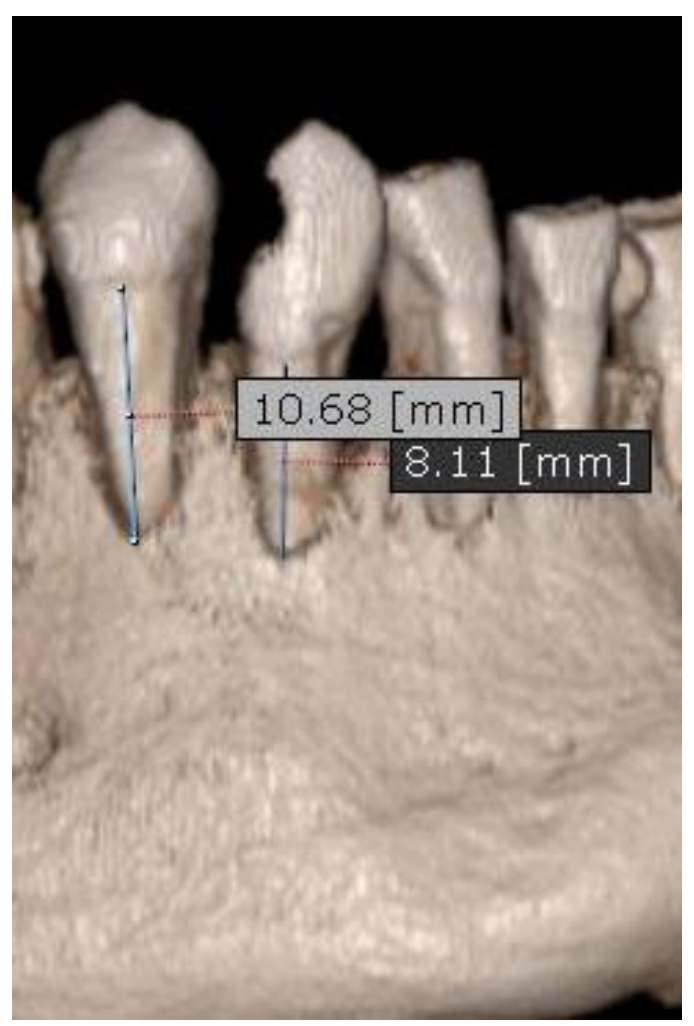

Fig. 2. Three-dimensional (3D) view of the cone-beam computed tomography (CBCT) scan illustrating dehiscences on a canine and on a first premolar
Measuring on radiographs followed the same protocol as measuring with a probe, considered here as the gold standard. Two calibrated observers (1 radiologist and 1 periodontist), who did not know where the defects were located, carried out the measurements. They assessed image sets at a 1-week interval and the assessment was repeated 1 week after first viewing. Inter- and intra-observer agreement was calculated with the intraclass correlation coefficient (ICC). It was also applied for CBCT-probe and PSP-probe to figure out which method had a higher correlation with the gold standard (according to the defect type and in total).

\section{Results}

According to $I C C$, the agreement degree between the observers who evaluated image sets was 0.93. Intraobserver agreement was calculated at 0.95 for the $1^{\text {st }}$ observer and at 0.88 for the $2^{\text {nd }}$ observer.

Based on the defect type, ICC was calculated for CBCT -probe, PSP-probe and CBCT-PSP. Table 1 shows that for all defect types, $\mathrm{CBCT}$ performed better in measuring the dimensions of the defects and had a higher correlation with the gold standard method (probe). Digital imaging was unable to detect dehiscences and fenestrations.

Based on the overall analysis of the data, CBCT showed a higher agreement degree and correlation with the probe than with digital imaging (Table 2).

Table 2. Intraclass correlation coefficient (ICC) in the evaluation of cone-beam computed tomography (CBCT) and photostimulable phosphor plates (PSP)

\begin{tabular}{|c|c|c|}
\hline Image modality & ICC & $p$-value \\
\hline CBCT-probe & 0.93 & 0.00 \\
\hline PSP-probe & 0.78 & 0.00 \\
CBCT-PSP & 0.77 & 0.00 \\
\hline
\end{tabular}

Table 1. Intraclass correlation coefficient (ICC) and the mean defect dimensions [mm] calculated for each method according to the defect type

\begin{tabular}{|c|c|c|c|c|c|c|}
\hline \multirow{2}{*}{$\begin{array}{l}\text { Defect type } \\
\qquad N=236\end{array}$} & \multicolumn{3}{|c|}{ ICC } & \multicolumn{3}{|c|}{ Mean defect dimensions [mm] } \\
\hline & CBCT -probe & PSP -probe & CBCT-PSP & probe & $\mathrm{CBCT}$ & PSP \\
\hline $\begin{array}{l}\text { Horizontal } \\
n=86\end{array}$ & $\begin{array}{c}0.92 \\
p=0.00\end{array}$ & $\begin{array}{c}0.73 \\
p=0.00\end{array}$ & $\begin{array}{c}0.66 \\
p=0.00\end{array}$ & $5.45 \pm 2.58$ & $5.93 \pm 2.94$ & $5.46 \pm 2.31$ \\
\hline $\begin{array}{l}\text { One-wall } \\
n=30\end{array}$ & $\begin{array}{c}0.94 \\
p=0.00\end{array}$ & $\begin{array}{c}0.64 \\
p=0.00\end{array}$ & $\begin{array}{c}0.62 \\
p=0.00\end{array}$ & $8.91 \pm 4.66$ & $8.74 \pm 4.02$ & $8.88 \pm 3.51$ \\
\hline $\begin{array}{l}\text { Two-wall } \\
n=20\end{array}$ & $\begin{array}{c}0.73 \\
p=0.00\end{array}$ & $\begin{array}{c}0.62 \\
p=0.00\end{array}$ & $\begin{array}{c}0.87 \\
p=0.00\end{array}$ & $10.52 \pm 2.88$ & $10.25 \pm 2.13$ & $10.81 \pm 2.12$ \\
\hline $\begin{array}{l}\text { Three-wall } \\
n=22\end{array}$ & $\begin{array}{c}0.82 \\
p=0.00\end{array}$ & $\begin{array}{c}0.77 \\
p=0.00\end{array}$ & $\begin{array}{c}0.78 \\
p=0.00\end{array}$ & $8.31 \pm 2.37$ & $9.00 \pm 2.79$ & $9.39 \pm 2.89$ \\
\hline $\begin{array}{l}\text { Crater } \\
n=22\end{array}$ & $\begin{array}{c}0.94 \\
p=0.00\end{array}$ & $\begin{array}{c}0.71 \\
p=0.00\end{array}$ & $\begin{array}{c}0.81 \\
p=0.00\end{array}$ & $7.63 \pm 2.73$ & $7.15 \pm 2.97$ & $8.01 \pm 2.70$ \\
\hline $\begin{array}{l}\text { Dehiscence } \\
n=32\end{array}$ & $\begin{array}{c}0.92 \\
p=0.00\end{array}$ & - & - & $8.09 \pm 1.83$ & $8.93 \pm 1.78$ & - \\
\hline $\begin{array}{l}\text { Fenestration } \\
n=24\end{array}$ & $\begin{array}{c}0.81 \\
p=0.00\end{array}$ & - & - & $1.72 \pm 0.31$ & $2.15 \pm 0.33$ & - \\
\hline
\end{tabular}

Data presented as mean $(M) \pm$ standard deviation $(S D)$.

$\mathrm{CBCT}$ - cone-beam computed tomography; PSP - photostimulable phosphor plates. 


\section{Discussion}

Many studies have confirmed that CBCT is advantageous in several fields, such as implant site imaging, orthodontics or craniofacial surgery. ${ }^{15}$ Evaluating CBCT in the periodontal field, some studies have assessed the ability of CBCT just to detect periodontal defects ${ }^{16-19}$ and some have evaluated the diagnostic accuracy of CBCT in measuring the dimensions of periodontal defects. ${ }^{20,21}$

Comparing the diagnostic accuracy of a charge-coupled device (CCD) and CBCT, Vandenberghe et al. examined both the panoramic reconstruction view and 0.4-millimeter cross-sectional slices of CBCT. ${ }^{2}$ They reported no significant differences in linear measurements between the panoramic reconstruction view of CBCT and CCD; however, $\mathrm{CBCT}$ with 0.4-millimeter-thick cross-sections demonstrated values closer to the gold standard, indicating a more accurate assessment of periodontal bone loss. ${ }^{2}$ Haghgoo et al. showed that CBCT was more accurate than CCD in evaluating the vertical dimensions of periodontal bone defects, but they reported no statistically significant differences. ${ }^{20}$ Silveira-Neto et al. assessed detail registration in the peri-implant region with CBCT and CCD for periapical digital radiography. ${ }^{22}$ They better detected buccal bone defects with CBCT and peri-implant bone defects with periapical digital radiography. ${ }^{22}$

Suphanantachat et al. compared conventional intraoral radiography and $\mathrm{CBCT}$ in assessing periodontal conditions and infrabony defects. ${ }^{19}$ They stated that CBCT was superior to intraoral radiography in evaluating infrabony defect morphology and providing treatment. ${ }^{19}$

The present study compared intraoral digital imaging (using PSP) and CBCT. A major advantage of the PSP image receptor is that it is cordless. This subsequently impacts the ease of receptor placement. According to the results, CBCT performed better than PSP, with a statistically significant difference in detecting and measuring periodontal defects.

Particularly, in measuring the horizontal pattern of bone loss, there was a higher correlation between CBCT and the gold standard than between PSP and the gold standard. In another study, CBCT also accurately reproduced the clinical measurement of the horizontal periodontal bone defect ${ }^{23}$; however, Haghgoo et al. found no significant difference in horizontal bone loss patterns between $\mathrm{CCD}$ and $\mathrm{CBCT}{ }^{20}$

Vandenberghe et al. demonstrated that crater defects are depicted more accurately with CBCT than with intraoral digital imaging, ${ }^{2}$ which is in agreement with our results.

Cone-beam computed tomography and intraoral digital imaging were compared with a direct surgical measurement in a study by Grimard et al. ${ }^{24}$; their conclusion is in agreement with ours, which is that $\mathrm{CBCT}$ shows a higher correlation with the gold standard.

Bayat et al. created defects in sheep mandibles and compared CBCT with PSP. ${ }^{17}$ They reported that CBCT was significantly superior in detecting grade I furcation involvements, three-wall defects, fenestrations, and dehiscences $(p<0.05)$. No significant difference was found in the detection of grades II and III furcation involvements, one-wall, two-wall, and trough-like defects ${ }^{17}$; however, in our study, CBCT was substantially more accurate in detecting and measuring all the examined periodontal defects. Ruetters et al. investigated the accuracy of CBCT and periapical digital radiography in comparison with clinical measurements for the vertical dimensions of periodontal bone defects, and showed that CBCT had a higher agreement with the clinical results and fewer deviations than periapical images. ${ }^{25}$

The detection of lingual or buccal defects, such as fenestrations and dehiscences, is difficult if not impossible, using $2 \mathrm{D}$ radiographs because of the superimposition of the root image. In these cases, CBCT is significantly superior to intraoral digital radiography, as mentioned by Mish et al. ${ }^{3}$ Similar to our study, in the results provided by Vandenberghe et al., 100\% detectability of periodontal defects with CBCT was confirmed, while intraoral digital imaging was not able to identify all defects. ${ }^{2}$ Fleiner et al. ${ }^{26}$ and Fuhrmann et al. ${ }^{27}$ also reported $100 \%$ detectability of periodontal defects. These findings differed from those of Braun et al. ${ }^{28}$ and Bagis et al. ${ }^{16}$ The percentage of the correct diagnoses of fenestration and dehiscence using $3 \mathrm{D}$ projections was very high, but not $100 \%$; however, they reported a superior diagnostic accuracy of CBCT over PSP. ${ }^{16,23}$ Mengel et al. also concluded that CBCT was closer to the histopathologic investigation. ${ }^{29}$

Noujeim et al. reported an excellent diagnostic accuracy of CBCT as compared to the 2D modality in the detection of inter-radicular bony defects. ${ }^{12} \mathrm{Mol}$ and Balasundaram ${ }^{10}$ and Bagis et al. ${ }^{16}$ also reported a better diagnostic and quantity accuracy of CBCT in comparison with PSP. Overall, the outcomes of this study revealed similar results to those of previous studies, indicating that CBCT exhibited a more accurate diagnostic ability than intraoral digital imaging with PSP sensors for detecting periodontal defects.

A substantial strength of this study was its comprehensiveness resulting from a large sample size (236 defects) and the evaluation of various types of periodontal defects. Using human mandibles was another advantage of the present study, while some other studies have used animal skulls, such as from pigs and sheep, whose anatomical differences may have affected diagnostic accuracy.

The in vitro design of the study can be considered a limitation, since there are differences between clinical conditions and in-vitro settings; however, Rost reported difficulty in measuring in vivo because of such factors as the patient's discomfort upon probing, inaccuracies in probing, probe angulation, and the impaired visualization due to the presence of subgingival calculus and inflamed gingivae. ${ }^{30}$ Artificially created periodontal defects are another limitation of this study, since burrs usually make distinctive borders, which may facilitate detection in imaging. 
Cone-beam computed tomography provided more diagnostic and quantity accuracy with regard to periodontal defects. It can be used as an additional tool for diagnosing and offering treatment plans for patients with periodontal bone defects. Even though the radiation dose of CBCT is higher in comparison to other modalities, nowadays the effective dosage of radiation can be decreased to $34 \mu \mathrm{S}$ by choosing smaller FOVs. ${ }^{31}$ If such progress continues and the radiation dose can be reduced to that of a panoramic view, the use of CBCT may be developed in the future. Further investigations are needed to examine other $\mathrm{CBCT}$ units and protocols with such factors as cost and conformance taken under consideration. Also, more studies should be conducted to assess and compare different resembling methods for soft tissue simulation.

\section{Conclusions}

CBCT is superior to digital intraoral radiography in detecting and measuring horizontal, one-, two- and threewall defects, craters, dehiscences, and fenestrations.

\section{ORCID iDs}

Mehrdad Abdinian (1) https://orcid.org/0000-0002-6893-8121 Jaber Yaghini (1) https://orcid.org/0000-0003-1775-3343 Leila Jazi @ isttps://orcid.org/0000-0002-3735-4764

\section{References}

1. Pihlstrom BL, Michalowicz BS, Johnson NW. Periodontal diseases. Lancet. 2005;366(9499):1809-1820.

2. Vandenberghe B, Jacobs R, Yang J. Detection of periodontal bone loss using digital intraoral and cone beam computed tomography images: An in vitro assessment of bony and/or infrabony defects. Dentomaxillofac Radiol. 2008;37(5):252-260.

3. Misch KA, Yi ES, Sarment DP. Accuracy of cone beam computed tomography for periodontal defect measurements. J Periodontol. 2006;77(7):1261-1266.

4. Armitage GC. The complete periodontal examination. Periodontol 2000. 2004;34:22-33.

5. Newman MG, Takei H, Klokkevold PR, Carranza FA. Carranza's Clinical Periodontology. $11^{\text {th }}$ ed. Philadelphia, PA: Saunders (Elsevier Health Sciences); 2011:144.

6. Jeffcoat MK, Reddy MS. Advances in measurements of periodontal bone and attachment loss. Monogr Oral Sci. 2000;17:56-72.

7. Versteeg $\mathrm{CH}$, Sanderink GC, van der Stelt PF. Efficacy of digital intraoral radiography in clinical dentistry. J Dent. 1997;25(3-4):215-224.

8. Eickholz P, Hausmann E. Accuracy of radiographic assessment of interproximal bone loss in intrabony defects using linear measurements. Eur J Oral Sci. 2000;108(1):70-73.

9. Zaki H, Hoffmann KR, Hausmann E, Scannapieco FA. Is radiologic assessment of alveolar crest height useful to monitor periodontal disease activity? Dent Clin North Am. 2015;59(4):859-872.

10. Mol A, Balasundaram A. In vitro cone beam computed tomography imaging of periodontal bone. Dentomaxillofac Radiol. 2008;37(6):319-324.

11. Tonetti MS, Pini Prato G, Williams RC, Cortellini P. Periodontal regeneration of human infrabony defects. III. Diagnostic strategies to detect bone gain. J Periodontol. 1993;64(4):269-277.

12. Noujeim M, Prihoda TJ, Langlais R, Nummikoski P. Evaluation of highresolution cone beam computed tomography in the detection of simulated interradicular bone lesions. Dentomaxillofac Radiol. 2009;38(3):156-162.
13. Kao RT, Nares S, Reynolds MA. Periodontal regeneration - intrabony defects: A systematic review from the AAP Regeneration Workshop. J Periodontol. 2015;86(2 Suppl):S77-S104.

14. Nikolic-Jakoba N, Spin-Neto R, Wenzel A. Cone-beam computed tomography for detection of intrabony and furcation defects: A systematic review based on a hierarchical model for diagnostic efficacy. J Periodontol. 2016;87(6):630-644.

15. Gil Choi IG, Gonzalez Cortes AR, Arita ES, Pauperió Georgetti MA. Comparison of conventional imaging techniques and CBCT for periodontal evaluation: A systematic review. Imaging Sci Dent. 2018;48(2):79-86.

16. Bagis N, Kolsuz ME, Kursun S, Orhan K. Comparison of intraoral radiography and cone-beam computed tomography for the detection of periodontal defects: An in vitro study. BMC Oral Health. 2015;15:64.

17. Bayat S, Talaeipour AR, Sarlati F. Detection of simulated periodontal defects using cone-beam CT and digital intraoral radiography. Dentomaxillofac Radiol. 2016;45(6):20160030.

18. Almeida VC, Pinheiro LR, Sales Salineiro FC, et al. Performance of cone beam computed tomography and conventional intraoral radiographs in detecting interproximal alveolar bone lesions: A study in pig mandibles. BMC Oral Health. 2017;17:100.

19. Suphanantachat S, Tantikul K, Tamsailom S, Kosalagood P, Nisapakultorn K, Tavedhikul K. Comparison of clinical values between cone beam computed tomography and conventional intraoral radiography in periodontal and infrabony defect assessment. Dentomaxillofac Radiol. 2017;46(6):20160461.

20. Haghgoo JM, Shokri A, Khodadoustan A, Khoshhal M, Rabienejad N, Farhadian M. Comparison the accuracy of the cone-beam computed tomography with digital direct intraoral radiography, in assessment of periodontal osseous lesions. Avicenna J Dent Res. 2014;6:e21952.

21. Leung CC, Palomo L, Griffith R, Hans MG. Accuracy and reliability of cone-beam computed tomography for measuring alveolar bone height and detecting bony dehiscences and fenestrations. Am J Orthod Dentofacial Orthop. 2010;137(4 Suppl):S109-S119.

22. Silveira-Neto N, Flores ME, De Carli JP, et al. Peri-implant assessment via cone beam computed tomography and digital periapical radiography: An ex vivo study. Clinics (Sao Paulo). 2017;72(11):708-713.

23. Feijo CV, Feitosa de Lucena JG, Kurita LM, da Silva Pereira SL. Evaluation of cone beam computed tomography in the detection of horizontal periodontal bone defects: An in vivo study. Int J Periodontics Restorative Dent. 2012;32(5):e162-e168.

24. Grimard BA, Hoidal MJ, Mills MP, Mellonig JT, Nummikoski PV, Mealey BL. Comparison of clinical, periapical radiograph, and cone-beam volume tomography measurement techniques for assessing bone level changes following regenerative periodontal therapy. J Periodontol. 2009;80(1):48-55.

25. Ruetters M, Hagenfeld D, ElSayed N, Zimmermann N, Gehrig $H_{\text {, }}$ Kim TS. Ex vivo comparison of CBCT and digital periapical radiographs for the quantitative assessment of periodontal defects. Clin Oral Investig. 2020;24(1):377-384 (Epub 2019).

26. Fleiner J, Hannig C, Schulze D, Stricker A, Jacobs R. Digital method for quantification of circumferential periodontal bone level using cone beam CT. Clin Oral Investig. 2013;17(2):389-396.

27. Fuhrmann RA, Wehrbein $H$, Langen HJ, Diedrich PR. Assessment of the dentate alveolar process with high resolution computed tomography. Dentomaxillofac Radiol. 1995;24(1):50-54.

28. Braun X, Ritter $L$, Jervøe-Storm PM, Frentzen M. Diagnostic accuracy of CBCT for periodontal lesions. Clin Oral Investig. 2014;18(4):1229-1236.

29. Mengel R, Candir M, Shiratori K, Flores-de-Jacoby L. Digital volume tomography in the diagnosis of periodontal defects: An in vitro study on native pig and human mandibles. J Periodontol. 2005;76(5):665-673.

30. Rost A. Using CBCT as a diagnostic tool for evaluation of infrabony defects in vivo. In: Department of Periodontics. Richmond, VA: Virginia Commonwealth University; 2014:35.

31. Horner K, Islam M, Flygare L, Tsiklakis K, Whaites E. Basic principles for use of dental cone beam computed tomography: Consensus guidelines of the European Academy of Dental and Maxillofacial Radiology. Dentomaxillofac Radiol. 2009;38(4):187-195. 
